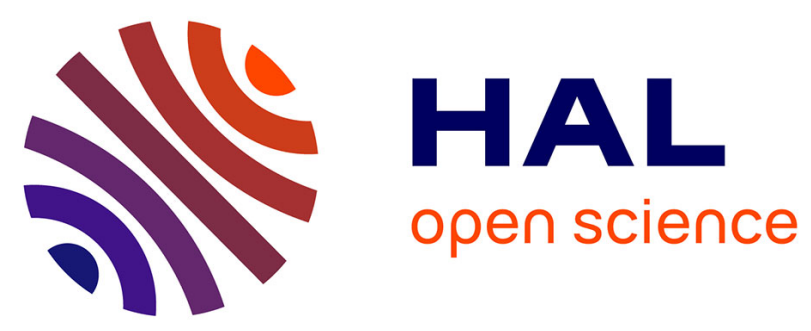

\title{
Spectral correlation of four wave mixing generated in a photonic crystal fiber pumped by a chirped pulse
}

Paul Robert, Coralie Fourcade-Dutin, Romain Dauliat, Raphaël Jamier, Hector Muñoz-Marco, Pere Perez-Millan, John M Dudley, Philippe Roy, Herve Maillotte, Damien Bigourd

\section{To cite this version:}

Paul Robert, Coralie Fourcade-Dutin, Romain Dauliat, Raphaël Jamier, Hector Muñoz-Marco, et al.. Spectral correlation of four wave mixing generated in a photonic crystal fiber pumped by a chirped pulse. Optics Letters, 2020, 45 (15), pp.4148-4151. 10.1364/OL.398614 . hal-02965800

\section{HAL Id: hal-02965800 https://hal.science/hal-02965800}

Submitted on 13 Oct 2020

HAL is a multi-disciplinary open access archive for the deposit and dissemination of scientific research documents, whether they are published or not. The documents may come from teaching and research institutions in France or abroad, or from public or private research centers.
L'archive ouverte pluridisciplinaire HAL, est destinée au dépôt et à la diffusion de documents scientifiques de niveau recherche, publiés ou non, émanant des établissements d'enseignement et de recherche français ou étrangers, des laboratoires publics ou privés. 


\title{
Spectral correlation of four wave mixing generated in a photonic crystal fiber pumped by a chirped pulse
}

\author{
Paul Robert, ${ }^{1}$ Coralie Fourcade-Dutin, ${ }^{1-2}$ Romain Dauliat, ${ }^{3}$ Raphael \\ Jamier, ${ }^{3}$ Hector Muñoz-Marco, ${ }^{4}$ Pere Perez-Millan, ${ }^{4}$ John M. Dudley, ${ }^{1}$ \\ Philippe Roy, ${ }^{3}$ Herve Maillotte, ${ }^{1}$ Damien Bigourd ${ }^{1-2^{*}}$ \\ ${ }^{1}$ Institut FEMTO-ST, Département d'Optique, UMR CNRS 6174 -Université Bourgogne Franche-Comté, 25030 Besançon, France \\ ${ }^{2}$ Laboratoire IMS, UMR CNRS 5218, University of Bordeaux, 33400 Talence, France \\ ${ }^{3}$ Université Limoges, XLIM, UMR CNRS 7252, F-87000 Limoges, France \\ ${ }^{4}$ FYLA LASER SL, Ronda Guglielmo Marconi 12, 46980, Paterna (Valencia), Spain \\ *Corresponding author: damien.bigourd@u-bordeaux.fr
}

Received XX Month XXXX; revised XX Month, XXXX; accepted XX Month XXXX; posted XX Month XXXX (Doc. ID XXXXX); published XX Month XXXX

The spectral correlation of four-wave mixing in a photonic crystal fiber pumped by a chirped pulse has been measured using the dispersive Fourier transform method. From statistical measurements of multiple shot-to-shot spectral measurements, the spectral correlation between the signal and idler photons reveals physical insights into the particular portion of the pump spectrum responsible for generating the FWM

\section{(C) 2020 Optical Society of America}

http://dx.doi.org/10.1364/OL.99.099999

Pulse amplification through four wave mixing (FWM) in optical fiber has been extensively investigated for important applications linked with its large gain-bandwidth [1], high gain [2] and very wide tunability [3]. When the pulses involved in the process have a high peak power, the pulses are initially stretched before being injected in the fiber $[4,5,6]$ such that the FWM process can be achieved in a fiber with a silica core, even for a pulse energy in the microjoule level $[7,8,9]$. For a chirped pump pulse, the instantaneous frequencies are temporally dispersed and the spontaneous photons are generated with temporal and spectral distributions according to phasematched FWM relation [10]. Significantly, we have shown that this configuration yields a very large gain bandwidth [2] that enables ultra-short pulse amplification [1]. However, the injected signal requires chirp optimization to match the temporal distribution of the parametric gain spectrum, which depends on both the pump and fiber properties [1]. Therefore, this parametric gain distribution needs to be understood and characterized to efficiently design a broadband amplifier.

Although some previous studies have used a pump-probe technique to study the gain distribution, this method is experimentally complex, which limits it broad use in studying chirped-pulse FWM over wider parameter ranges [11]. In this work, we present a much simpler approach that allows the spectral and temporal distribution of the instantaneous parametric process to be studied using the dispersive Fourier transformation (DFT) method [12]. This powerful technique is significantly simpler to implement since it provides the desired information without the need to inject a suitable signal, and also readily allows statistical correlation data to be extracted.

The DFT method exploits time to frequency mapping to allow real time measurement of single-shot spectral fluctuations. DFT has been widely used to study a range of physical processes in fiber such as rogue wave dynamics, continuum generation and spontaneous FWM [13-18]. In our case, we use DFT to measure the spectral correlation between the FWM side bands generated from a chirped pump pulse, representing a new application of this method, and one which allows us to determine physical insights into the particular portion of the pump spectrum responsible for generating the FWM. In particular, for degenerate FWM, two pump photons are converted to signal and idler photons, with spontaneous generation achieved from different possibilities depending on phase matching criteria. This leads to an asymmetry in the FWM band in a single shot spectrum measurement [16]. Once the shots are averaged, the shape of the spontaneous FWM spectrum should represent the gain profile of the parametric amplification in the unsaturated regime. In the following, we exploit the DFT statistical measurements over many single shot spectra to correlate the signal and idler photons and to infer the origin of the FWM within the pump.

We firstly illustrate the principle of this method using numerical simulations based on integrating the nonlinear Schrödinger equation using the split step method. The parameters used were as follows. The input chirped pump pulse has duration of $\Delta \mathrm{t}=50 \mathrm{ps}$ and spectral bandwidth $\Delta \lambda$ of $6 \mathrm{~nm}$ centered at $1030 \mathrm{~nm}$. This corresponds to a chirp of $\Delta \tau / \Delta \lambda=-8.3 \mathrm{ps} / \mathrm{nm}$. The pulse is injected in a 5-meter-long photonic crystal fiber (PCF) which has a nonlinear 
coefficient of $11 \mathrm{~W}^{-1} \cdot \mathrm{km}^{-1}$ and a zero-dispersion wavelength (ZDW) at $1028 \mathrm{~nm}$. This means that only part of the pump spectrum lies in the anomalous dispersion regime. 500 simulations have been performed with random noise initial condition by adding half photon per temporal mode. Figure 1 shows a spectrogram of the average electric field at the fiber output for input peak power $\mathrm{Pp}=120 \mathrm{~W}$. The red line corresponds to the pump pulse. As it is chirped, the instantaneous pump wavelengths are linearly spread in the temporal envelope. The temporal and spectral axis (top and bottom) are therefore linked by the chirp value; i.e $\Delta \tau / \Delta \lambda$. For each delay, the pump has a particular instantaneous wavelength and a pump power that creates a FWM with specific properties [2]. Indeed, two specific FWM bands are generated with different spectral locations and bandwidth. For example, at the pump wavelengths of $1030 \mathrm{~nm}(\mathrm{t}=0 \mathrm{ps})$ and $1032 \mathrm{~nm}(-16.6 \mathrm{ps})$, the two lobes are located at $\sim 1078 / 986 \mathrm{~nm}$ and 1061/998nm, respectively.

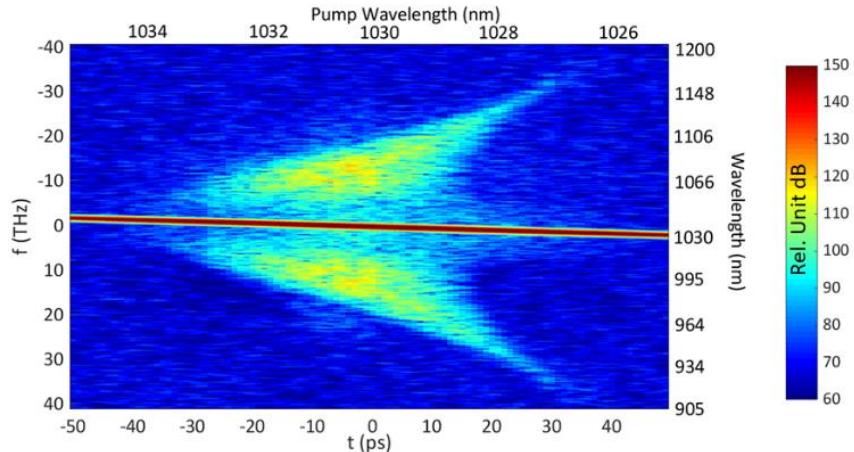

Fig. 1. Spectrogram of the averaged electric field at the PCF output for $\mathrm{Pp}=120 \mathrm{~W}$

To analyse the shot to shot fluctuations statistically, the spectral correlation $\rho\left(\lambda_{1}, \lambda_{2}\right)$ has been calculated between any two wavelengths $\lambda_{1}$ and $\lambda_{2}$ according to

$$
\rho\left(\lambda_{1}, \lambda_{2}\right)=\frac{\left\langle I\left(\lambda_{1}\right) I\left(\lambda_{2}\right)\right\rangle-\left\langle I\left(\lambda_{1}\right)\right\rangle\left\langle I\left(\lambda_{2}\right)\right\rangle}{\sqrt{\left\langle I^{2}\left(\lambda_{1}\right)\right\rangle-\left\langle I\left(\lambda_{1}\right)\right\rangle^{2} \cdot\left\langle I^{2}\left(\lambda_{2}\right)\right\rangle-\left\langle I\left(\lambda_{2}\right)\right\rangle^{2}}}
$$

where the angle brackets represent an ensemble average. The correlation $\rho$ varies from -1 to +1 indicating intensity fluctuations in the opposite or same directions respectively. For $\rho=0$, no correlation exists between $\lambda_{1}$ and $\lambda_{2}$. The spectral correlation between the lower and higher parts of the spectrum is shown in Fig. 2 together with the average spectra. The red line (top-right) corresponds to the positive correlation of the pump spectrum with itself; i.e the auto-correlation. Since the FWM process is originated from a depletion of the pump, the correlation between the side bands and the pump is negatively correlated ( $\rho \sim-0.3)$.

As the two axes represent the wavelength of the signal $\lambda_{s}$ and idler $\lambda_{i}$, the theoretical relationship of FWM from energy conservation $\left(2 / \lambda_{p}=1 / \lambda_{s}+1 / \lambda_{i}\right)$ can be also plotted. The black curves in Fig. 2 represent three cases for a selection of pump wavelengths $\lambda_{p}$, and we can see from these results how it is possible to infer the particular pump component, which generates the FWM bands. For example, when the fiber is pumped by a chirped pulse with $\mathrm{Pp}=120$ W (Fig. 2(a)), the bands at $\sim 980 \mathrm{~nm}$ and $1000 \mathrm{~nm}$ are mostly generated from the pump part at $1030 \mathrm{~nm}$ lying in the anomalous dispersion regime. The photons in the range of 930-980 $\mathrm{nm}$ and $1090-1140 \mathrm{~nm}$ are generated from the pump between 1025-1030 $\mathrm{nm}$. These observations are in very good agreement with those from the spectrogram (Fig. 1). We have also checked that the Raman effect does not affect this distribution.
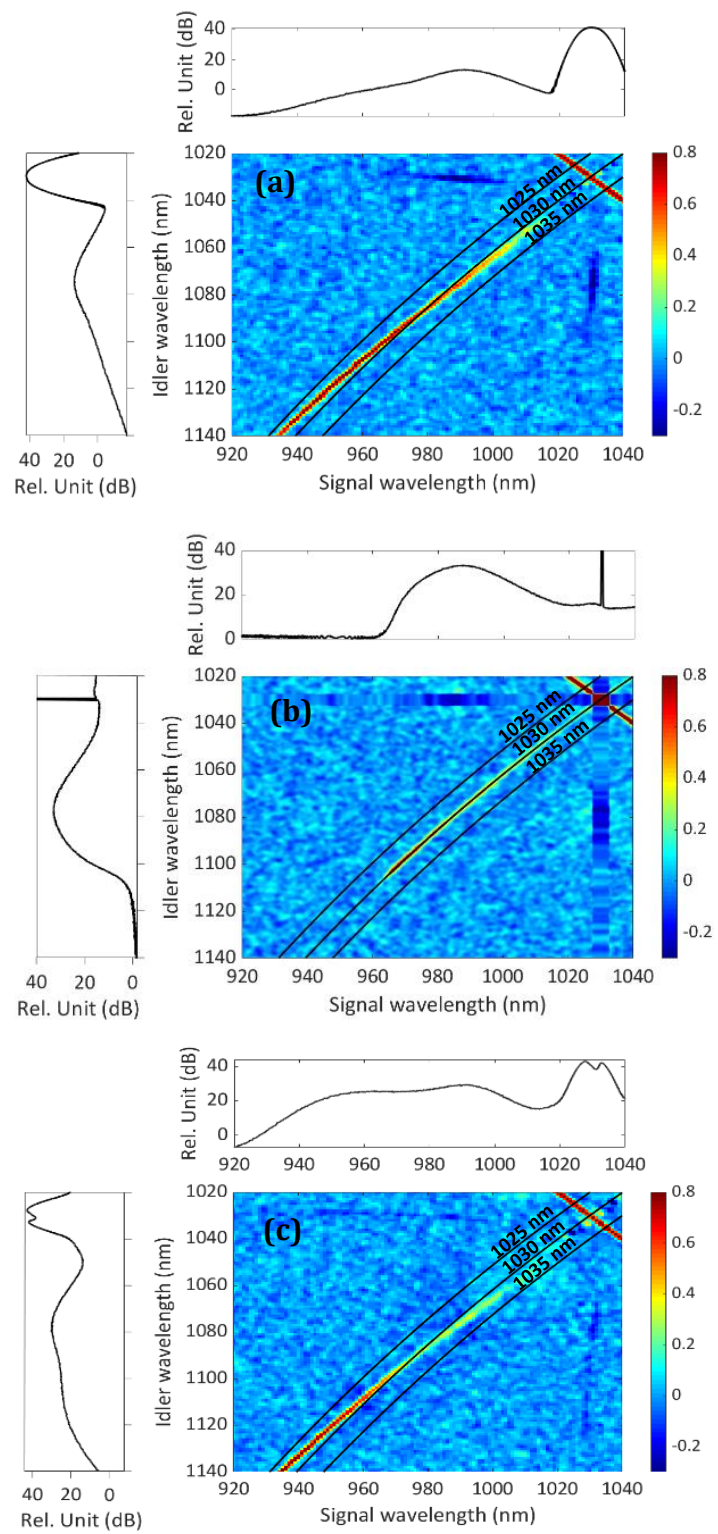

Fig. 2. Spectral correlation between the Stokes and Anti-Stokes for a) $\mathrm{Pp}=120 \mathrm{~W}$ and a chirped pump pulse, b) for $\mathrm{Pp}=120 \mathrm{~W}$ and a monochromatic pump c) for $\mathrm{Pp}=220 \mathrm{~W}$ and a chirped pump pulse. The average spectra are displayed for all cases as top and left inserts. The black lines are plotted from the photon energy conservation law for several pump wavelengths.

To gain further insight, we performed the simulations under the same conditions but with a monochromatic pump (Fig. 2(b)). Compared to the previous case, the bandwidths are lower since the FWM photons are generated from the pump with a narrow spectrum. Indeed, the spectral correlation is along the black line plotted from the energy conservation law for $\lambda_{\mathrm{p}}=1030 \mathrm{~nm}$. The numerical results for a chirped pulse with $\mathrm{Pp}=220 \mathrm{~W}$ (Fig. 2(c)) show that the FWM bands increase and the pump is affected by self 
phase modulation (SPM). In this case, the $\rho$ value decreases for the pump wavelength higher than $1030 \mathrm{~nm}$ and corresponds to the hole in the pump spectrum.

Our experimental setup is shown in Fig. 3a. The pump pulse is generated from a mode-locked oscillator (Flint, LightConversion) delivering a train of pulses at $76 \mathrm{MHz}$ with a duration of $80 \mathrm{fs}$ at FWHM centered at $1030 \mathrm{~nm}$. The total average power is $1.5 \mathrm{~W}$. A part of the oscillator output (around $750 \mathrm{~mW}$ ) seeds the pump chain via a stretching stage composed of a volume Bragg grating (VBG) that stretches the pulses to a duration of 50 ps (FWHM), an acoustooptic modulator (AOM) to decrease the repetition rate to 1 $\mathrm{MHz}$ and several ytterbium doped fiber amplifiers (YDFA) to progressively increase the average power up to $1 \mathrm{~W}$. The pulse bandwidth (FWHM) at the output of the amplifier is $\sim 9 \mathrm{~nm}$ and is modulated due to SPM. The pump pulse is then injected in a 5meter-long PCF which has the same dispersion profile as the one used in the simulations. Two FWM lobes are generated in the PCF and are located at 1001 and $1071 \mathrm{~nm}$ for an average power of 18 $\mathrm{mW}$ (Fig. 3(b)).

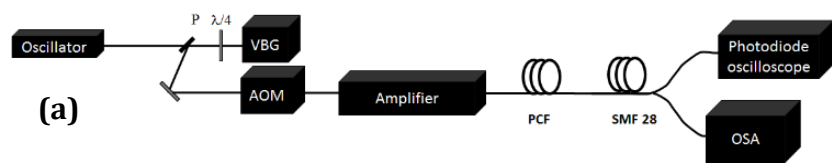

(b)

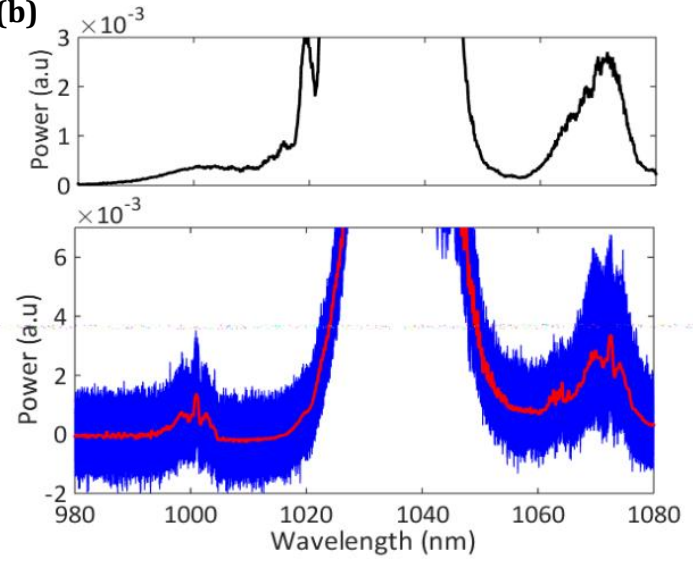

Fig. 3. Experimental set-up. VBG, Volume Bragg Grating; AOM, acoustooptic modulator; PCF Photonic Crystal Fiber; OSA, Optical Spectrum Analyzer et b)FWM bands detected with an OSA (black line) and with the DFT set-up. The averaged spectrum (red line) of 500 single shots (blue lines) are displayed.

In order to record single shot spectra, a dispersive Fourier transform set-up has been implemented at the PCF output. The beam is injected in an $11.5 \mathrm{~km}$ long fiber (SMF28) to stretch the output with approximate chirp value of $\sim-2.54 \mathrm{~nm} / \mathrm{ns}$. Thus, the delay between the two sidebands is $\sim 27 \mathrm{~ns}$. The output is detected with a fast photodiode and an oscilloscope with a maximum bandwidth of $12 \mathrm{GHz}$. For the following, we use a limited number of points to $5 \times 106$ for the 500 pulses corresponding to a spectral resolution of $\sim 0.25 \mathrm{~nm}$. Figure 3(b) displays the superposition of 500 single shot spectra (blue lines) and the averaged curve. To accurately reconstruct the DFT time-frequency mapping, we used both second and third order dispersion coefficients of the SMF $\left(\beta_{2}=17 \mathrm{ps}^{2} / \mathrm{km}, \beta_{3}=-0.0134 \mathrm{ps}^{3} / \mathrm{km}\right)$ in the analysis of the experimental data [12]. From Figure 3(b) (blue lines), we can see the large shot to shot fluctuation of the sideband but a good agreement is obtained between the average spectrum (red line) and the curve measured by an optical spectrum analyzer (black line). Figure 4 shows the spectral correlation map between 980 and $1090 \mathrm{~nm}$ for an average power of $24 \mathrm{~mW}$. As expected, the pump spectrum is positively correlated with itself and the correlation between two identical FWM bands corresponds to a positive line with a maximum $\rho$ value equal to 1 . From Eq. 1, the correlation map is symmetric about the correlated positive diagonal. As the Stokes and anti-Stokes photons are degenerate from the depletion of the pump pulse, an anti-correlation between the pump and the two side lobes are observed (black dashed squares) [13]. In the following, we will focus on the correlation between the two FWM bands (black squares).
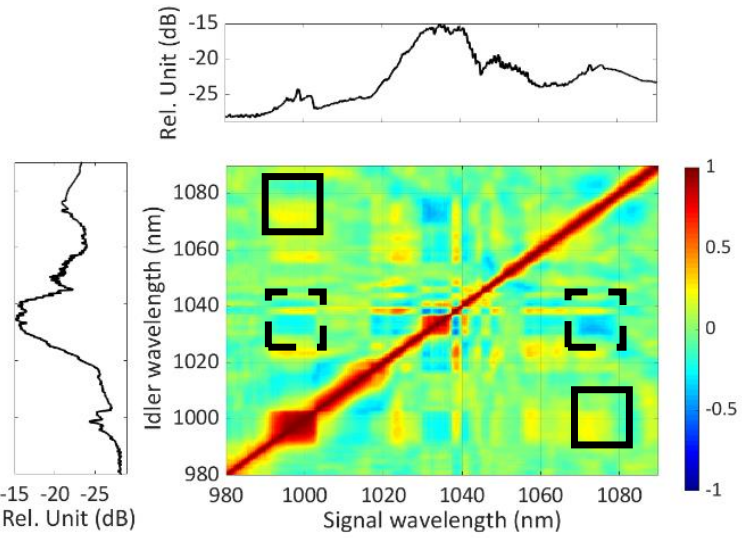

Fig. 4. Spectral correlation map of the full spectrum for a power of $24 \mathrm{~mW}$. The black dashed squares correspond to the correlation between the pump and the FWM bands while the black squares show the correlation between the two bands.

The spectral correlations between the two side bands (black squares in Fig. 4) are also shown in Fig. 5 for an average power of $18 \mathrm{~mW}$ and $24 \mathrm{~mW}$. The black lines are plotted from the photon energy conservation law for the pump wavelength of 1025, 1030 and $1035 \mathrm{~nm}$. The correlation spectral maps have a different shape from the one predicted by the numerical simulations (Fig. 2), attributed to structure on the pump pulse used in the experiments or uncertainties in the fiber dispersion curve. From a pump-probe experiment [11], we have also observed similar behavior with another PCF. At a power of $18 \mathrm{~mW}$, a positive value is observed with a specific shape. The maximum at $\rho \sim 0.4$ corresponds to the correlation between the two parts 1068-1071nm/990-997nm. These parts of the bands are mainly generated from the pump spectrum around $1030 \mathrm{~nm}$. Another positive $\rho$ value $(\sim 0.25)$ located between 1073-1075/997-1002 is also obtained and these FWM bands are mostly generated from the pump spectrum at $\sim 1035 \mathrm{~nm}$. Surprisingly, the correlated bands are not symmetric around the pump spectrum; i.e the furthest part in one side is correlated to the closest part in the other side. This information cannot be obtained directly from a standard spectrometer.

At higher pump power, the side bands are shifted away from the pump and the positive correlation is mainly between 1070-1075 $\mathrm{nm}$ and $995-1005 \mathrm{~nm}$. A negative correlation value $(\rho=-0.15)$ at around $1082 \mathrm{~nm}$ is also observed. This is attributed to SPM accumulated by the pump that decreases the correlation value. 
From the black line (Fig. 5(b)), we can deduce that it originates from the pump spectrum at $>1035 \mathrm{~nm}$. Indeed, a spectral hole in the pump is observed at $1037 \mathrm{~nm}$ (Fig. 4) and is consistent with the signature of the decrease in correlation as expected from the simulations.
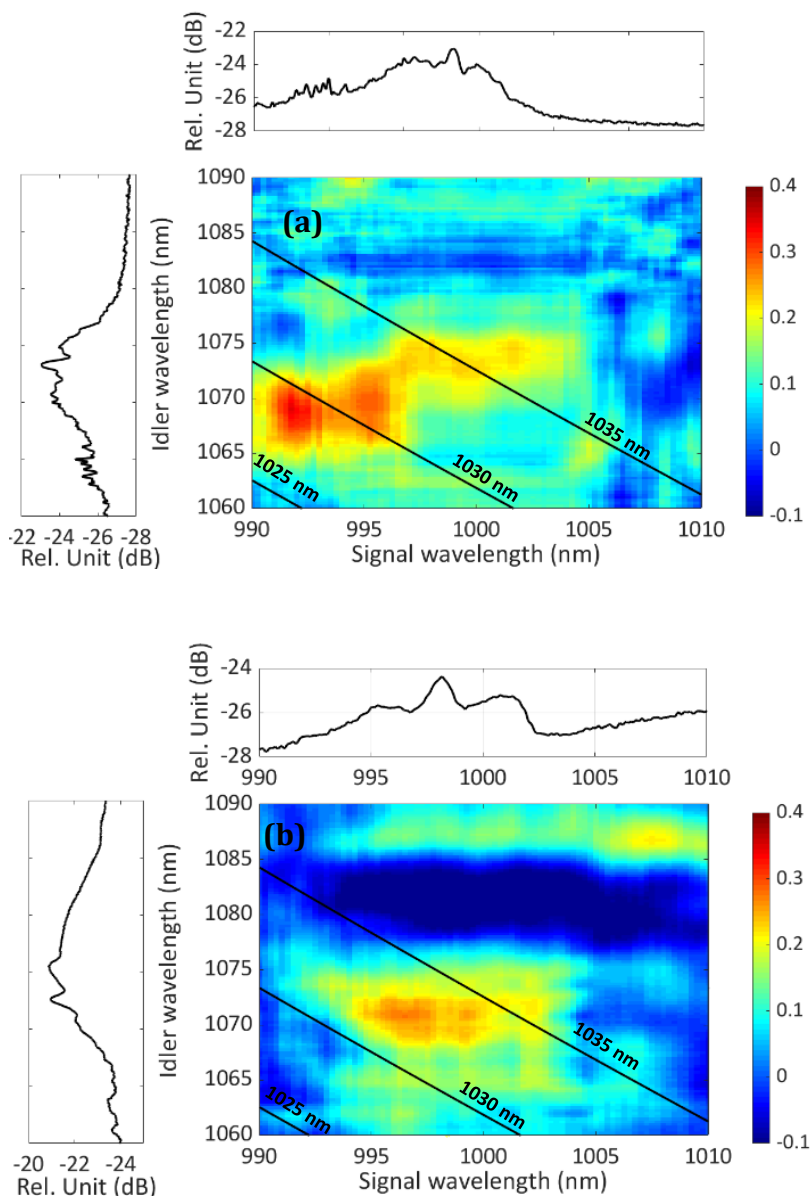

Fig. 5. Spectral correlation between the Stokes and Anti-Stokes for a power of $18 \mathrm{~mW}$ (a) and $24 \mathrm{~mW}$ (b). The average spectrum are displayed for each cases. The black lines are plotted from the photon energy conservation law for several pump wavelengths.

In conclusion, we have shown that the DFT method can be implemented to measure the spectral correlation between side bands. In the case of a chirped pump pulse, the spectral correlation map can be used to infer the pump part that generated the FWM. This method is relatively straightforward since it requires only one pump pulse without any seed injection. In addition, the statistical analysis provides significant new information and therefore the DFT method can be used as a highly complementary diagnostic to standard spectrometers. We believe that it will be of prime interest for the development of fiber amplifier supporting a very broad bandwidth [1].
Funding. ANR (ANR-16-CE2460009, ANR-17-EURE-0002, ANR10-IDEX-03-02), Bourgogne Franche-Comté councils (SUM Project).

Acknowledgment. We thank C. Billet for helpful advice and T. Sylvestre for loan of the fiber spool used in the DFT experiments.

Disclosures. The authors declare no conflicts of interest.

\section{REFERENCES}

1. C Fourcade-Dutin, O Vanvincq, A Mussot, E Hugonnot and D Bigourd, J. Opt. Soc. Am B 32, 1488 (2015).

2. O Vanvincq, C Fourcade-Dutin, A Mussot, E Hugonnot and D Bigourd, J. Opt. Soc. Am B 32, 1479 (2015).

3. Y. Zhou, K. K. Y. Cheung, S. Yang, P. C. Chui and K. K. Y. Wong, Opt Lett. 34, 989 (2009).

4. D. Bigourd, L. Lago, A. Mussot, A. Kudlinski, J.F. Gleyze and E. Hugonnot, Opt. Lett. 35, 3840 (2010).

5. Y. Qin, O. Batjargal, B. Cromey and K. Kieu, Opt. Exp. 28, 2317 (2020).

6. Y. Qin, Y.H Ou, B. Cromey, O. Batjargal, J. K. Barton and K. Kieu, Opt. Lett. 44, 3422 (2019).

7. W. Fu and F.W. Wise, Opt. Lett. 43, 5331 (2018).

8. P. Morin, J. Dubertrand, P. Beaure d'Augeres, Y. Quiquempois, G. Bouwmans, A. Mussot and E. Hugonnot, Opt. Lett. 43, 4683 (2018).

9. D. Bigourd, P. Morin, J. Dubertrand, C. Fourcade-Dutin, H. Maillotte, Y Quiquempois, G. Bouwmans and E. Hugonnot, IEEE Photon. Technol. Lett. 31, 214 (2018).

10. D. Bigourd, P. Beaure d'Augeres, J. Dubertrand, E. Hugonnot and A. Mussot, Opt. Lett. 39, 3782 (2014).

11. C. Fourcade-Dutin, A. Imperio, R. Dauliat, R. Jamier, H. MuñozMarco, P. Pérez-Millán, H. Maillotte, P. Roy and D. Bigourd, Photonics 6, 20 (2019).

12. K. Goda and B. Jalali, Nat. Photonics 7, 102 (2013).

13. P. Béjot, J. Kasparian, E. Salmon, R. Ackermann and J.-P Wolf, Appl. Phys. B 87, 1 (2007).

14. B. Wetzel, A. Stefani, L. Larger, P. A. Lacourt, J. M. Merolla, T. Sylvestre, A. Kudlinski, A. Mussot, G. Genty, F. Dias and J. M. Dudley, Sc. Reports 2, 882 (2012).

15. M. Narhi, B. Wetzel, C. Billet, S. Toenger, T. Sylvestre, J.M. Merolla R. Morandotti, F. Dias, G. Genty and J. Dudley, Nat. Communications 7, 13675 (2016).

16. D. R. Solli, G. Herink, B. Jalali and C. Ropers, Nat. Photonics 6, 463 (2012).

17. X. Wang, D. Bigourd, A. Kudlinski,K. K. Y. Wong, M. Douay, L. Bigot, A Lerouge, Y. Quiquempois, and A. Mussot, Opt. Lett. 39, 1881 (2014).

18. T. Godin, B. Wetzel, T. Sylvestre, L. Larger, A. Kudlinski, A. Mussot, A. Ben Salem, M. Zghal, G. Genty, F. Dias, and J. M. Dudley, Opt. Exp. 21, 18452 (2013). 


\section{REFERENCES}

1. C Fourcade-Dutin, O Vanvincq, A Mussot, E Hugonnot, D Bigourd, "Ultrabroadband fiber optical parametric amplifiers pumped by chirped pulses. Part 2: sub-30 fs pulse amplification at high gain," J. Opt. Soc. Am B 32, 1488 (2015).

2. O Vanvincq, C Fourcade-Dutin, A Mussot, E Hugonnot, D Bigourd, "Ultrabroadband fiber optical parametric amplifiers pumped by chirped pulses. Part 1: analytical model,” J. Opt. Soc. Am B 32, 1479 (2015).

3. Y. Zhou, K. K. Y. Cheung, S. Yang, P. C. Chui, K. K. Y. Wong, "Widely tunable picosecond optical parametric oscillator using highly nonlinear fiber," Opt. Lett. 34, 989 (2009).

4. D. Bigourd, L. Lago, A. Mussot, A. Kudlinski, J.F. Gleyze, E. Hugonnot, "High-gain fiber optical parametric chirped pulse amplification of femtosecond pulses at $1 \mu \mathrm{m}$," Opt. Lett. 35, 3840 (2010).

5. Y. Qin, O. Batjargal, B. Cromey, K. Kieu, "All-fiber high-power $1700 \mathrm{~nm}$ femtosecond laser based on optical parametric chirped-pulse amplification, ” Opt. Exp. 28, $2317(2020)$

6. Y. Qin, Y.H Ou, B. Cromey, O. Batjargal, J. K. Barton, K. Kieu, “Watt-level all-fiber optical parametric chirped-pulse amplifier working at $1300 \mathrm{~nm}$, , Opt. Lett. 44, 3422 (2019).

7. W. Fu, F.W. Wise, “Normal-dispersion fiber optical parametric chirped-pulse amplification,” Opt. Lett. 43, 5331 (2018).

8. P. Morin, J. Dubertrand, P. Beaure d’Augeres, Y. Quiquempois, G. Bouwmans, A. Mussot, E. Hugonnot, “ $\mu$ J-level Raman-assisted fiber optical parametric chirped-pulse amplification," Opt. Lett. 43, 4683 (2018).

9. D. Bigourd, P. Morin, J. Dubertrand, C. Fourcade-Dutin, H. Maillotte, Y Quiquempois, G. Bouwmans, E. Hugonnot, "Parametric gain shaping from a structured pump pulse," IEEE Photon. Technol. Lett. 31, 214 (2018).

10. D. Bigourd, P. Beaure d'Augeres, J. Dubertrand, E. Hugonnot, A. Mussot, "Ultra-broadband fiber optical parametric amplifier pumped by chirped pulses," Opt. Lett. 39, 3782 (2014).

11. C. Fourcade-Dutin, A. Imperio, R. Dauliat, R. Jamier, H. Muñoz-Marco, P. Pérez-Millán, H. Maillotte, P. Roy, D. Bigourd, “Temporal Distribution Measurement of the Parametric Spectral Gain in a Photonic Crystal Fiber Pumped by a Chirped Pulse," Photonics 6, 20 (2019).

12. K. Goda and B. Jalali, "Dispersive Fourier transform for fast continuous single-shot measurements," Nature Photonics 7, 102 (2013).

13. P. Béjot, J. Kasparian, E. Salmon, R. Ackermann, J.-P Wolf, “Spectral correlation and noise reduction in laser filaments," Appl. Phys. B 87, 1 (2007).

14. B. Wetzel, A. Stefani, L. Larger, P. A. Lacourt, J. M. Merolla, T. Sylvestre, A. Kudlinski, A. Mussot, G. Genty, F. Dias, J. M. Dudley,

"Real-time full bandwidth measurement of spectral noise in supercontinuum generation," Scientific Reports 2, 882 (2012).

15. M. Narhi, B. Wetzel; C. Billet, S. Toenger, T. Sylvestre, J.M. Merolla, R. Morandotti, F. Dias, G. Genty, J. Dudley, "Real-time measurements of spontaneous breathers and rogue wave events in optical fibre modulation instability," Nat. Communication 7, 13675 (2016).

16. D. R. Solli, G. Herink, B. Jalali and C. Ropers, "Fluctuations and correlations in modulation Instability," Nature Photonics 6, 463 (2012).

17. X. Wang, D. Bigourd, A. Kudlinski,K. K. Y. Wong, M. Douay, L. Bigot, A. Lerouge, Y. Quiquempois, and A. Mussot, "Correlation between multiple modulation instability side lobes in dispersion oscillating fiber," Opt. Lett. 39, 1881 (2014).

18. T. Godin, B. Wetzel, T. Sylvestre, L. Larger, A. Kudlinski, A. Mussot, A. Ben Salem, M. Zghal, G. Genty, F. Dias, and J. M. Dudley, "Real time noise and wavelength correlations in octave-spanning supercontinuum generation," Opt. Exp. 21, 18452 (2013). 
